\title{
Prognostication of heart failure development and advance: the role of high-sensitive ST2
}

\author{
Alexander E. Berezin* \\ Internal Medicine Department, State Medical University, Ukraine
}

\begin{abstract}
Currently the care of patients with heart failure (HF) may base on clinical- and biomarker-guided therapy. Natriuretic peptides, high-sensitive cardiac troponins, galectin-3 were recognized to the evolution and outcome of cardiac diseases. Recently trials have shown that circulating level of soluble ST2 (sST2) measured at predischarge might have predictive value in short-term outcomes and probably long-term mortality among subjects with acute and chronic HF. Although preliminary results of clinical studies on this novel biomarker are encouraging, its role in the risk stratification in HF is needed to establish. The short comment reports that the prognostic performance of elevated sST2 with respect to cardiovascular $(\mathrm{CV})$ mortality and newly diagnosed HF in general patient population is currently limited to a number of modest-quality studies and is required to be assessed in large comprehensive trials. The predictive value of sST2 appears to be superior compared with $\mathrm{BNP}$ and similar to galectin-3 among subjects with none-CV diseases is discussed. The role of elevated sST2 level as independent predictor of outcomes in HF population is considered.
\end{abstract}

\begin{abstract}
Abbreviations: BNP: brain natriuretic peptide; CV: cardiovascular; HF: heart failure; IL: interleukin; NYHA : New york heart association

Heart failure (HF) remains a leading cause of cardiovascular (CV) mortality worldwide [1]. Over the past decades, the clinical use of multiple biomarkers has changed diagnostic and management of CV disease [2]. Current clinical guidelines have recommended to use single and serial biomarker measurements for diagnostic purpose, risk stratification and guided-therapy of patients with acute and chronic HF $[3,4]$. Natriuretic peptides, high-sensitive cardiac troponins, galectin-3 were recognized to the evolution and outcome of cardiac diseases [5-7]. Recently trials have shown that circulating level of soluble ST2 (sST2) measured at pre-discharge might have predictive value in short-term outcomes and probably long-term mortality among subjects with acute and chronic HF [8-10]. Although preliminary results of clinical studies on this novel biomarker are encouraging, its role in the risk stratification in HF is needed to establish.
\end{abstract}

sST2 is a member of interleukin-1 receptor family that is secreted from cardiomyocytes and cardiac fibroblasts due to biomechanical stress and volume overload [11]. ST2 is expressed on Th2 cells and may regulate Th2 responses mediating inflammation and appears to act as a decoy receptor for IL-33 [12]. Overall sST2 is considered a biomarker of ventricular fibrosis, remodeling and inflammation [9].

Although concentration of sST2 correlates well with brain natriuretic peptide (BNP) levels in HF patients, in fact, circulating sST2 levels were not significantly changed according to the degree of renal dysfunction $[13,14]$. This fact was considered an advantage of sST2 compared with other markers of biomechanical stress (natriuretic peptides), inflammation (galectin-3) and myocardial injury (cardiac specific troponins) in HF individuals. It has been postulated that sST2 added to other biomarkers might improve multiple biomarker strategy for risk stratification of death in a real-life HF and increase efficacy of biomarker-guided care based on BNP measurements in combination with established HF mortality risk factors (age, sex, left ventricular ejection fraction, NYHA class, ischemic HF etiology, diabetes, estimated glomerular filtration rate, sodium level, hemoglobin level) $[15,16]$. Unfortunately, elevation of sST2 in circulation is not specific for $\mathrm{HF}$ and has not a powerful diagnostic effect on presentation of cardiac dysfunction unless reduced left ventricular ejection fraction $[17,18]$. In this context, there are prompts regarding use of sST2 in combination with other inflammatory biomarkers, i.e. galectin-3, and growth-differentiation factor-15, to increase sensitivity and specificity of multiple biomarker models in diagnostic of HF including asymptomatic stage and HF with preserved left ventricular ejection fraction $[19,20]$. As a result of similar approach, we have a large body of evidence regarding extending prognostication value of sST2 added to cardiac biomarkers, such as BNP, in none cardiovascular patients [2123]. Inversely, in a healthy general population from Finland, sST2 did not improve long-term prediction of cardiovascular events including heart failure or all-cause mortality [24]. Thus, sST2 appears to not be able to identify individuals with elevated CV risk and add to existing $\mathrm{CV}$ risk prediction algorithms.

In conclusion, the diagnostic capacities of sST2 to identify HF due to lower specificity compared BNP is not discussed, although utility sST2 incorporated into multiple biomarker models in diagnostic of HF, especially in patients with kidney dysfunction, diabetes, older age, is mentioned attractive. The prognostic performance of elevated sST2 with respect to CV mortality and newly diagnosed HF in general

Correspondence to: Alexander E. Berezin, MD, PhD, Consultant of Cardiology Unit, Internal Medicine Department, State Medical University, 26, Mayakovsky av., Zaporozhye, Ukraine, Postcode 69035; Tel: +380612894585; E-mail: dr_berezin@mail.ru

Key words: soluble ST2, heart failure, prediction, outcomes, risk stratification

Received: October 26, 2015; Accepted: November 13, 2015; Published: November 16, 2015 
patient population is currently limited to a number of modest-quality studies and is required to be assessed in large comprehensive trials. The predictive value of sST2 appears to be superior compared with BNP and similar to galectin-3 among subjects with none-CV diseases. However, in spite of the fact that elevated sST2 level has found an independent predictor of clinical outcomes in HF population, its role in the guided management of HF patients is still not clear. Overall, larger randomized clinical trials are necessary to assess the value of peak concentration and serial measurements of sST2 in HF to improve prediction of outcomes and management.

\section{References}

1. Mozaffarian D, Benjamin EJ, Go AS, Arnett DK, Blaha MJ, et al. (2015) Heart disease and stroke statistics--2015 update: a report from the American Heart Association. Circulation 131: e29-322. [Crossref]

2. Myers GL, Christenson RH, Cushman M, Ballantyne CM, Cooper GR, et al. (2009) National Academy of Clinical Biochemistry Laboratory Medicine Practice guidelines: emerging biomarkers for primary prevention of cardiovascular disease. Clin Chem 55: 378-384. [Crossref]

3. McMurray JJ, Adamopoulos S, Anker SD, Auricchio A, Bohm M, et al. (2012) ESC guidelines for the diagnosis and treatment of acute and chronic heart failure : The Task Force for the Diagnosis and Treatment of Acute and Chronic Heart Failure 2012 of the European Society of Cardiology. Developed in collaboration with the Heart Failure Association (HFA) of the ESC. Eur J Heart Failure 14: 803-869. [Crossref]

4. Yancy CW, Jessup M, Bozkurt B, Butler J, Casey DE, et al. (2013) ACCF/AHA guideline for the management of heart failure: a report of the American College of Cardiology Foundation/American Heart Association Task Force on practice guidelines. Circulation 128: e240-e327. [Crossref]

5. Gupta DK, Wang TJ (2015) Natriuretic Peptides and Cardiometabolic Health. Circ J 79: 1647-1655. [Crossref]

6. McCullough PA, Olobatoke A, Vanhecke TE (2011) Galectin-3: a novel blood test for the evaluation and management of patients with heart failure. Rev Cardiovasc Med 12: 200-210. [Crossref]

7. Coats CJ, Heywood WE, Mills K, Elliott PM (2015) Current applications of biomarkers in cardiomyopathies. Expert Rev Cardiovasc Ther 13: 825-837. [Crossref]

8. Kaye DM, Mariani JA, van Empel V, Maeder MT (2014) Determinants and implications of elevated soluble ST2 levels in heart failure. Int J Cardiol 176: 1242-1243. [Crossref]

9. Lupu S, Agoston-Coldea L (2015) Soluble ST2 in Ventricular Dysfunction. Adv Clin Chem 69: 139-159. [Crossref]

10. Kim MS, Jeong TD, Han SB, Min WK2, Kim JJ (2015) Role of Soluble ST2 as a Prognostic Marker in Patients with Acute Heart Failure and Renal Insufficiency. $J$ Korean Med Sci 30: 569-575. [Crossref]
11. Dieplinger B, Januzzi JL Jr, Steinmair M, Gabriel C, Poelz W, et al. (2009) Analytical and clinical evaluation of a novel high-sensitivity assay for measurement of soluble ST2 in human plasma--the Presage ST2 assay. Clin Chim Acta 409: 33-40. [Crossref]

12. Martínez-Martínez E, Cachofeiro V, Rousseau E, Álvarez V, Calvier L, FernándezCelis A, et al. (2015) Interleukin-33/ST2 system attenuates aldosterone-induced adipogenesis and inflammation. Mol Cell Endocrinol 411: 20-7. [Crossref]

13. Bao YS, Na SP, Zhang P, Jia XB, Liu RC, et al. (2012) Characterization of interleukin-33 and soluble ST2 in serum and their association with disease severity in patients with chronic kidney disease. J Clin Immunol 32: 587-594. [Crossref]

14. Boisot S, Beede J, Isakson S, Chiu A, Clopton P, et al. (2008) Serial sampling of ST2 predicts 90-day mortality following destabilized heart failure. J Card Fail 14: 732-738. [Crossref]

15. Breidthardt T, Balmelli C, Twerenbold R, Mosimann T, Espinola J, et al. (2013) Heart failure therapy-induced early ST2 changes may offer long-term therapy guidance. $J$ Card Fail 19: 821-828. [Crossref]

16. Lupón J, de Antonio M, Galán A, Vila J, Zamora E, et al. (2013) Combined use of the novel biomarkers high-sensitivity troponin T and ST2 for heart failure risk stratification vs conventional assessment. Mayo Clin Proc 88: 234-243. [Crossref]

17. Brunner M, Krenn C, Roth G, Moser B, Dworschak M, et al. (2004) Increased levels of soluble ST2 protein and $\mathrm{IgG} 1$ production in patients with sepsis and trauma. Intensive Care Med 30: 1468-1473. [Crossref]

18. Lupón J, Gaggin HK, de Antonio M, Domingo M, Galán A, et al. (2015) Biomarkerassist score for reverse remodeling prediction in heart failure: The ST2-R2 score. Int $J$ Cardiol 184: 337-343. [Crossref]

19. Mueller T, Leitner I, Egger M, Haltmayer M, Dieplinger B (2015) Association of the biomarkers soluble ST2, galectin-3 and growth-differentiation factor-15 with heart failure and other non-cardiac diseases. Clin Chim Acta 445: 155-160. [Crossref]

20. Meluzín J, Tomandl J (2015) Can biomarkers help to diagnose early heart failure with preserved ejection fraction? Dis Markers 2015: 426045. [Crossref]

21. Dispenzieri A, Gertz MA, Saenger A, Kumar SK, et al. (2015) Soluble suppression of tumorigenicity 2 (sST2), but not galactin-3, adds to prognostication in patients with systemic AL amyloidosis independent of NT-proBNP and troponin T. Am J Hematol 90: 524-528. [Crossref]

22. Shen J, Shang Q, Wong CK, Li EK, Wang S, et al. (2015) IL-33 and soluble ST2 levels as novel predictors for remission and progression of carotid plaque in early rheumatoid arthritis: A prospective study. Semin Arthritis Rheum [Crossref]

23. Chaemsaithong P, Romero R, Tarca AL, Xu Z, Ahmed AI, Hassan SS, et al. (2015) When is maternal plasma sST2 concentration elevated in patients with preeclampsia? Pregnancy Hypertens 5: 27-8.

24. Hughes MF, Appelbaum S, Havulinna AS, Jagodzinski A, Zeller T, et al. (2014) ST2 may not be a useful predictor for incident cardiovascular events, heart failure and mortality. Heart 100: 1715-21. [Crossref]

Copyright: (C2015 Berezin AE. This is an open-access article distributed under the terms of the Creative Commons Attribution License, which permits unrestricted use, distribution, and reproduction in any medium, provided the original author and source are credited. 